\title{
Removing of heavymetals from water by chitosan nanoparticles
}

Mohamed A. Abd-Elhakeem*, Maha M. Ramadan, Faisal S. Basaad

College of Biotechnology, Misr University for Science and Technology, Giza, Egypt

Email: mohamed.abdelhakim@must.edu.eg

\section{Abstract:}

Chitosan was prepared by deacetylation of chitin. The prepared chitosan has characterized bymolecular weight, degree of deacetylation, and ash \%. Chitosan nanoparticles were prepared byionotropic gelation of chitosan with tripolyphosphate anions. The structure and particle size of chitosan nanoparticles have confirmed via FTIR analysis and TEM imaging. The chitosan nanoparticles were used in water treatment to remove metal ions from sample contains 20 ppm from each Fe ${ }^{+2}$, $\mathrm{Mn}^{+2}, \mathrm{Zn}^{+2}$ and $\mathrm{Cu}^{+2}$. The optimum conditions for this study were at $2 \mathrm{~g} / \mathrm{l}$ of chitosan nanoparticles, $\mathrm{pH} 7 \mathrm{and} 30 \mathrm{~min}$ of mixing time. Chitosan showed the highest performance under these conditions with removing percent $99.94 \% 80.85 \%$ $90.49 \%$ and $95.93 \%$ from $\mathrm{Fe}^{+2}, \mathrm{Mn}^{+2}, \mathrm{Zn}^{+2}$ and $\mathrm{Cu}^{+2}$ respectively.

Keywords:chitin; chitosan; heavy metals; water purification.

\section{Council for Innovative Research}

Peer Review Research Publishing System

\section{Journal: Journal of Advances in Chemistry}

Vol. 11, No. 7

editorjaconline@gmail.com, www.cirjac.com 


\section{Introduction}

Heavy metals often pollute the effluents of industrial wastewaters [1]. Drinking of heavy metals contaminated water results obvious toxicity in different organsand usually associated with different diseases [2].Due to the high cost of the present water treatment systems, most of the development countries populations already drink contaminated water [3].On the other hand the treatment of wastewater is an essential step to partially purification of industrial and agricultural wastewater before spelled in the drain. So introduction of a cheap and easy prepared water purification system has a social and economic importance.

Adsorption is the promising system for removing of heavy metals, especially using low-cost adsorbents like clay material, agricultural wastes and seafood processing wastes [4].

Chitosan is a natural polymer obtained from chitin(the characteristic component of the cell walls of fungi, the exoskeletons of arthropods and insects) through deacetylation in alkaline medium [5].Chitosan has drawn particular attention as effective biosorbent due to its low cost compared to activated carbonand its high contents of amino and hydroxyl functional groups showing high adsorption potential for various aquaticpollutants [6-11].

In the previous work [12] we introduced chitosan coated magnetic nanoparticles as an efficient chelating agent to removecopper, and lead individually. In the current study we investigated the efficiency of chitosan nanoparticles that are more suitable to use in water filter to remove simultaneously many metals in mixture sample.

\section{Materials and methods}

Shrimp shells will be obtained from local market,Sodium tripoly phosphate (TPP) was purchased, all reagents were of analytical grade and used without further purification.

\section{Preparation of chitosan}

The chitosan was prepared according to the method previously reported [13]. Shrimp shells were immediately washed several times with water and detergent then allowed to dry in open area under sunlight. The dry material was transformed into chitosan via three successive steps (demineralization, deproteinization, and deacetylation). Typically200 g grounded material were soaked in $1 \mathrm{~L} 1 \% \mathrm{HCl}$ for 24 hours to remove minerals then treated with $2 \% \mathrm{NaOH}$ solution to decompose the albumen into water soluble amino acids. The remaining chitin is washed with deionized water. The deacetylation process is carried out by adding $50 \% \mathrm{NaOH}$ solution then boiled at $100^{\circ} \mathrm{C}$ for $2 \mathrm{~h}$ on a hot plate. The remaining creamy white material was collected and air dried.

\section{Preparation of chitosan nanoparticles}

$1 \%(\mathrm{w} / \mathrm{v})$ solution from each Chitosan in $(2 \% \mathrm{w} / \mathrm{v})$ acetic acid and TPP in double distilled water were prepared. Chitosan nanoparticles were fabricated with the dropwise addition of $50 \mathrm{~mL}$ of the chitosan solution to $20 \mathrm{~mL}$ of TPP solution under magnetic stirring (1000 rpm, 1 hour) at room temperature. The formed nanoparticles were separated by centrifugation at $20,000 \mathrm{~g}$ and $14^{\circ} \mathrm{C}$ for 30 minutes, freeze-dried and stored at $4^{\circ} \mathrm{C}$ [14].

\section{Characterization of prepared chitosan}

The prepared chitosan was characterized by determination of molecular weight, Ash \%, and degree of deacetylation as described below. The IR analysis was performed using (JASCO FTIR 1600). TEM observation was performed on a microscope (JEOL JAM-2100-HR-EM).

\section{Determination of molecular weight:}

Average molecular weight of chitosan was determined by determination of its intrinsicviscosity by(Brook-field viscometer spindle $\mathrm{RV}-\mathrm{Vl}$ ). $1 \mathrm{mg} / \mathrm{ml}(\mathrm{w} / \mathrm{v})$ concentration of chitosan solution was prepared using $0.5 \mathrm{M}$ acetic acid - $0.2 \mathrm{M}$ sodium acetate. The average molecular weight was obtained from Mark-Houwink equation:

$$
\eta=K M^{a}
$$

Where $[\eta]$ is the intrinsic viscosity, $M$ is average molecular weight of the solution $\left(K=3.5 \times 10^{-4}\right)$ and $(\alpha=0.76)$ are the Mark-Houwink constants specific for a given polymer [15].

\section{Moisture and Ash\%:}

The moisture and ash \% were calculated depending on gravimetric analysis as described previously [16].

\section{Degree of deacetylation:}

The removal percent of acetyl group from the chitin chain or (degree of deacetylation)was determined using IR method and calculated based on the following equation [17]

$$
D A \%=\left[\left(A_{1655} / A_{3450}\right) \times 100\right] / 1.33
$$

Where: $D A \%$ is the percent of deacetylation, $A_{3450}$ and $A_{1655}$ are values of absorbance from baseline to maximum. 


\section{Batch adsorption experiments:}

Water solution of $20 \mathrm{ppm}$ of each $\mathrm{Fe}^{+2}, \mathrm{Mn}^{+2}, \mathrm{Cu}^{+2}$ and $\mathrm{Zn}^{+2}$ ions was prepared by dissolving proper weight from $\mathrm{Fe}\left(\mathrm{NO}_{3}\right)_{2}, \mathrm{MnSO}_{4} . \mathrm{H}_{2} \mathrm{O}, \mathrm{CuSO}_{4} .5 \mathrm{H}_{2} \mathrm{O}$ and $\mathrm{ZnSO}_{4} .7 \mathrm{H}_{2} \mathrm{O}$ respectivelyin double distilled water. The concentration of each metal was confirmed by analysis using flame atomic absorption spectrophotometry (Buck scientific VGP 210). The primary batch adsorption experiments were carried out in $250 \mathrm{ml}$ conical flask using $50 \mathrm{~mL}$ water sample and different weight of chitosan nanoparticles $(25-400 \mathrm{mg})$. The flasks were incubated at room temperature under constant agitation rate $100 \mathrm{rpm}$ and $\mathrm{pH}$ 4. After filtration, the concentration of metal ions in supernatant was analysed using flame atomic absorption spectrophotometry. The amount of metal removed was calculated as percent ofinitial concentration whilethe amount of adsorption was calculated based on the difference of ion concentration in aqueous solutions before and after adsorption, according to:

$$
(q \mathrm{e})=\left[\left(C_{0}-\mathrm{Ce}\right) \mathrm{V}\right] / W
$$

Where (qe) is the adsorption capacity $(\mathrm{mg} / \mathrm{g}) C_{0}$ is the initial ion concentration (ppm), Ce is the final or equilibrium concentration $(\mathrm{ppm}), V$ is the volume of the solution $(0.05 \mathrm{~L})$ and $W$ is the weight of chitosan. The effect of both $\mathrm{pH}$ (range 2-9) and agitation time (range 10-60 min.) was investigated at the best chitosan amount. Adsorption equilibrium studies were conducted at constant chitosan weight $(300 \mathrm{mg})$.

\section{Results and discussion}

\section{Chitosan characterization:}

Table 1 summarize the characterization of the prepared chitosan. The FTIR spectrum (umax $\mathrm{cm}^{-1}$ ) of chitosan shows a characteristic bands of chitosan at $3440 \mathrm{~cm}^{-1}$ (broad) for $\mathrm{NH}$, and $\mathrm{OH}$ groups, $2915 \mathrm{~cm}^{-1}$ for C-H stretching vibration and $1640 \mathrm{~cm}^{-1}$ (amide). TEM imaging (fig 1) shows that the chitosan nanoparticles are spherical and average size 40-60 nm

Table (1): characterization of chitosan

\begin{tabular}{ll}
\hline Yield \% & $39.40 \%$ \\
Solubility & $2 \%$ acetic acid \\
Moisture \% & 1.47 \\
Ash \% & 0.34 \\
Molecular weight & $152,236.75$ \\
Degree of deacetylation & $72.6 \%$ \\
\hline
\end{tabular}

\section{Batch adsorption experiments}

The presence of free amino group on chitosan chain allows the chelation of heavy metals that helps in water purification. Dosage of chitosan was an important parameter that has been considered for the optimization of the performance and cost evaluation of the treatment process. In our experiment (fig 2) the metals removal percentage increased with the chitosan amount up to equilibrium that achieved at $300 \mathrm{mg}$ chitosan.

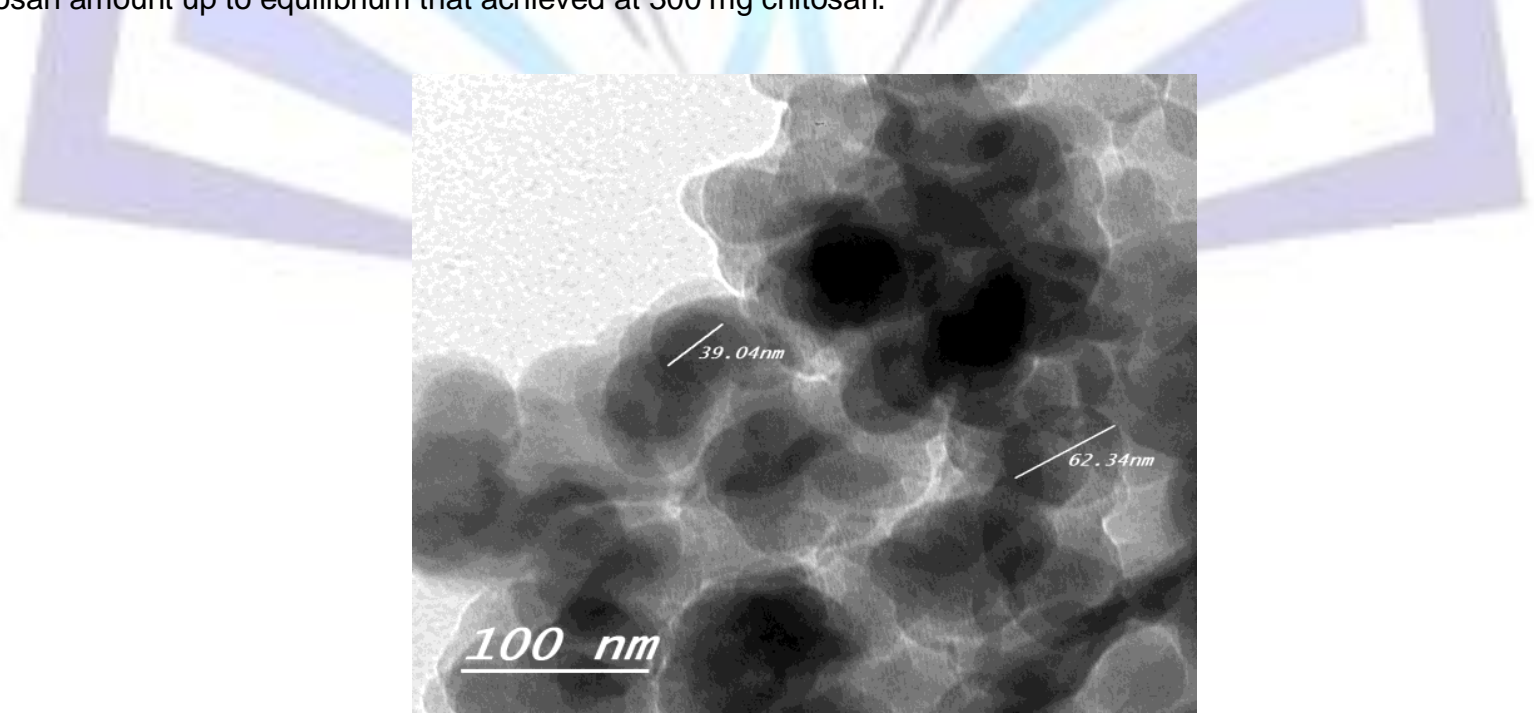

Fig (1): TEM image of chitosan nanoparticles 


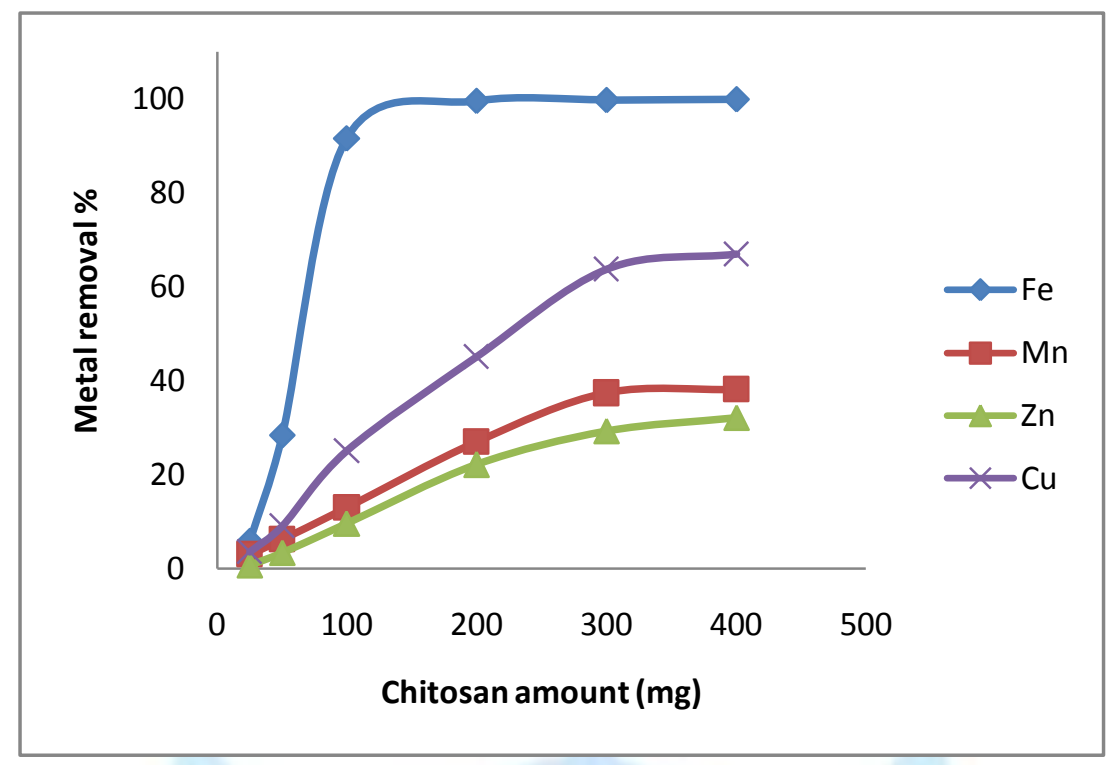

Fig (2): Effect of chitosan amount on metal removal \%

As Shown in fig. (3), the adsorption capacities $\left(q_{e}\right)$ of all metals increase with the chitosan amount till $100 \mathrm{mg}$ chitosan/50 $\mathrm{mL}$ then adsorption capacities markedly decrease with the chitosan concentration. This means: it is more efficient and economically preferred to use $100 \mathrm{mg}$ chitosan three times than use $300 \mathrm{mg}$ one time. However in this study, we have used $300 \mathrm{mg}$ in the followed experiments because it is less time consuming.

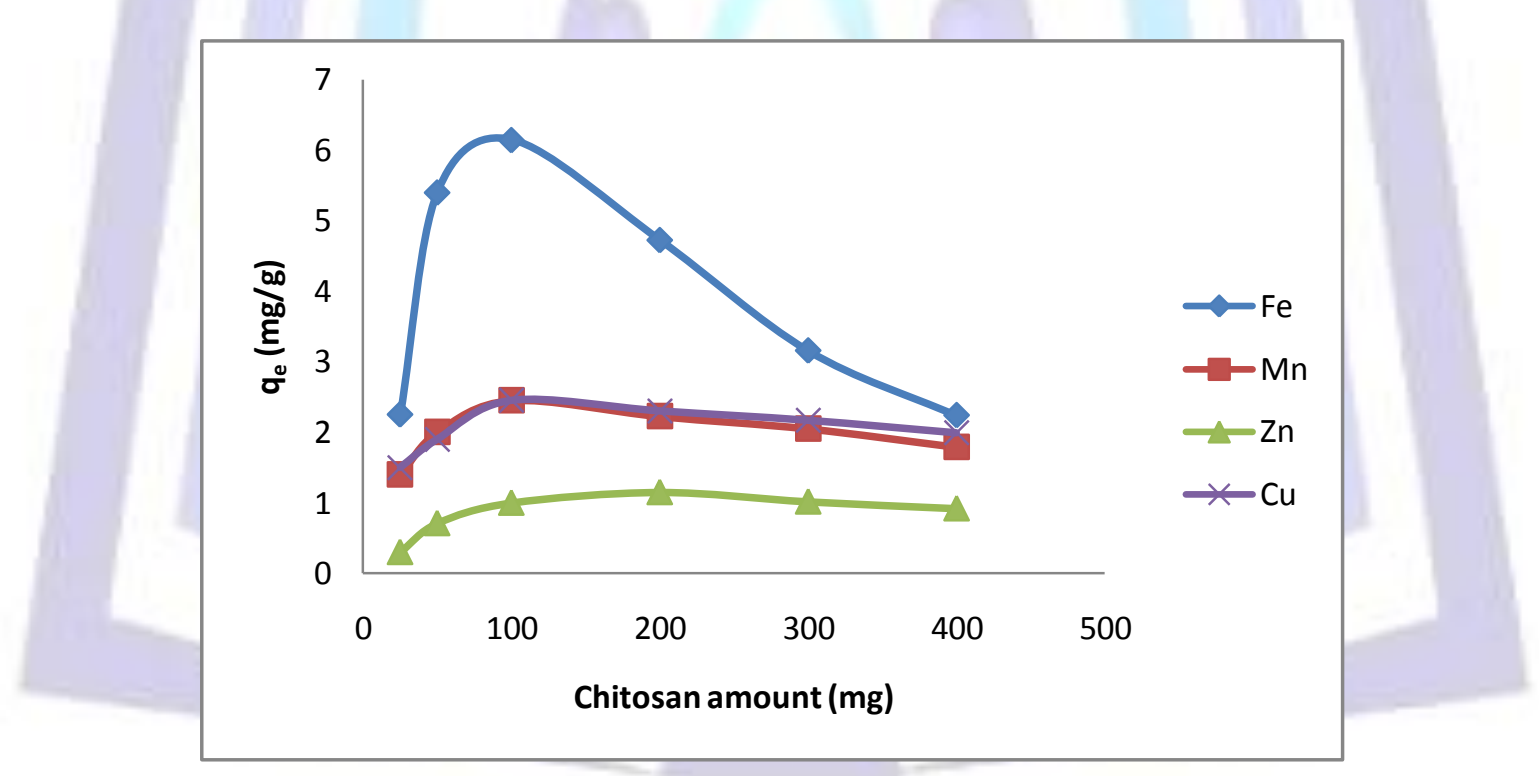

Fig (3): Effect of chitosan amount on adsorption of the metal ions

\section{Adsorption optimum conditions:}

The $\mathrm{pH}$ of solution strongly affects the adsorption capacity of the chitosan nanoparticles. This may be due to protonation of amino groups (at low $\mathrm{pH}$ ) causes reduction of the available number of binding sites for the adsorption. Fig. $4 \& 5$ show the effect of $\mathrm{pH}$ on the adsorption of metal ions by chitosan nanoparticles. The maximum adsorption was achieved at $\mathrm{pH} 7.0$. At $\mathrm{pH} 8$ and higher, a precipitation was noted due to formation of hydroxide of the metal ions so pH 8 and 9 were excluded. 


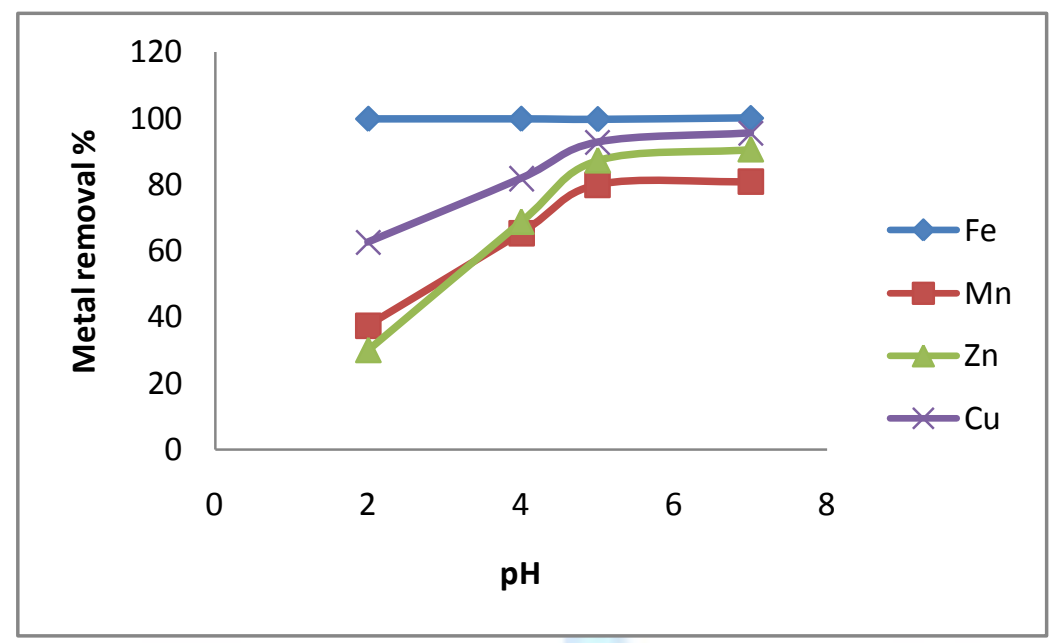

Fig (4): Effect of $\mathrm{pH}$ on metal ions removal \%

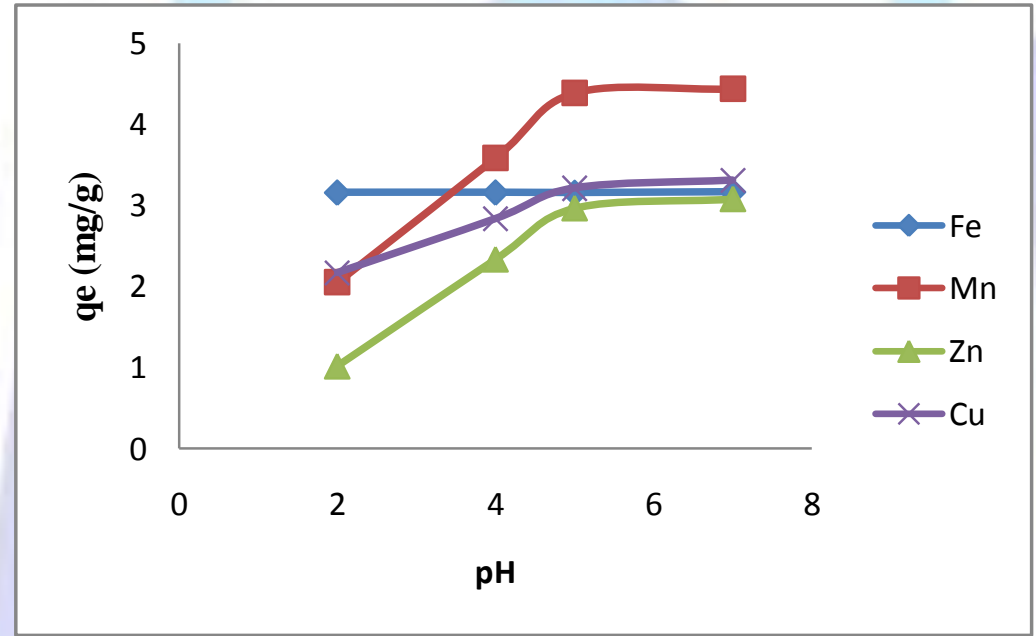

Fig (5): Effect of $\mathrm{pH}$ on adsorption of the metal ions

Fig. 6, 7shows the effect of agitation period on the adsorption of each metal ion by chitosan nanoparticles. Generally the adsorption increases withagitation period and attains equilibrium at about $30 \mathrm{~min}$ and it remained constant, implying equilibrium has beenreached.

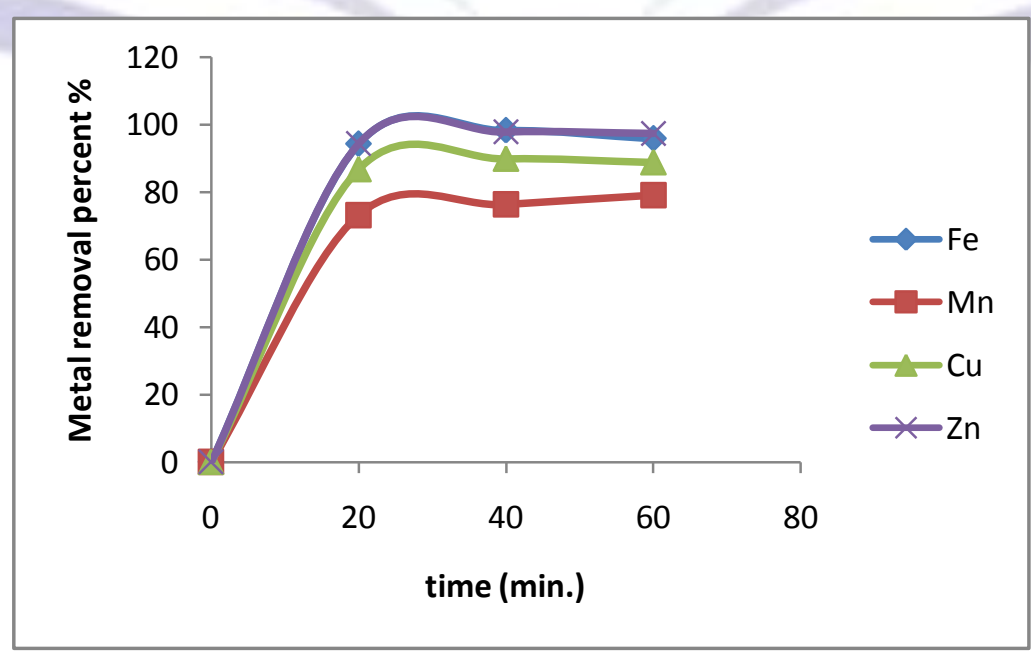

Fig (6): Effect of agitation time on metal ions removal \% 


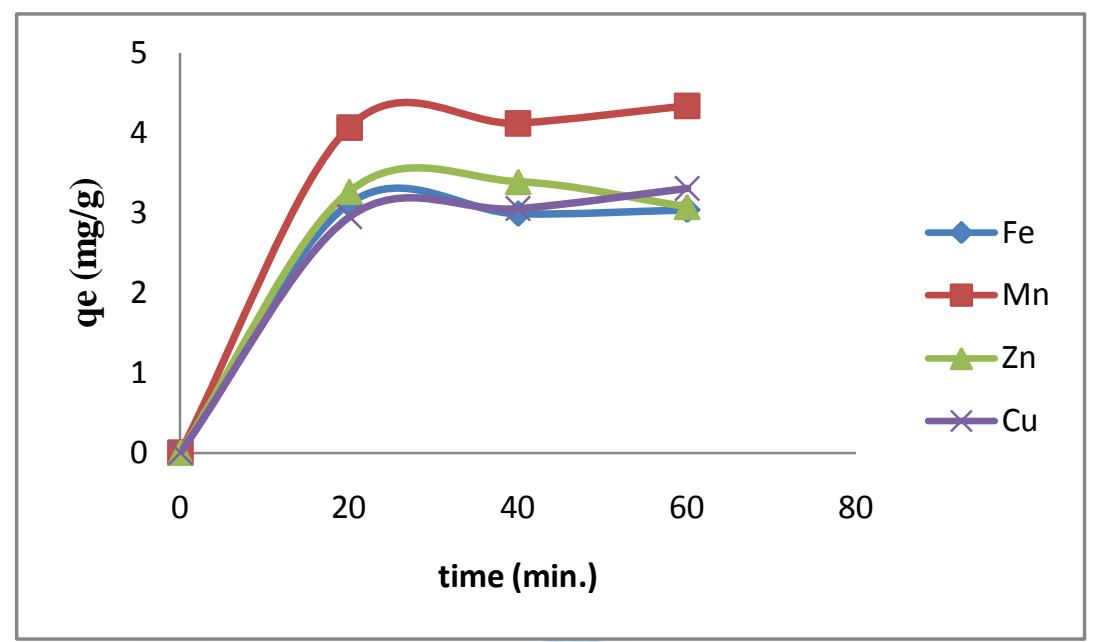

Fig (7): Effect of agitation time on adsorption of the metal ions

\section{Conclusion}

Chitosan and chitosan nanoparticles are successfully prepared. The result showed that chitosan nanoparticles are an effective adsorbent for heavy metal removing in multi-metal sample. Our results indicate that chitosan could be used in industrial wastewater treatment in a simple filtration system. Our study shows the optimum chitosan: sample volume ratio, $\mathrm{pH}$ and mixing time.

\section{References}

1. G. Crini, "Recent Developments in Polysaccharide-Base Materials used as adsorbents in wastewater treatment, Progress in Polymer Science, 30, 38-70 (2005).

2. A. M. Al-Attar, Antioxidant effect of vitamin $E$ treatment on some heavy metals-induced renal and testicular injuries in male mice, Saudi Journal of Biological Sciences, 18, (1), 63-72 (2011).

3. N. Abdel-Raouf, A.A. Al-Homaidan, I.B.M. Ibraheem, Microalgae and wastewater treatment, Saudi journal of biological sciences, 19(3), 257-275 (2012).

4. Yuh-Shan Ho, R. Malarvizhi,N. Sulochana, Equilibrium Isotherm Studies of Methylene Blue Adsorption onto Activated Carbon Prepared from Delonixregia Pods, Journal of environmental protection science, 3, 111 - 116 (2009).

5. Kh. Z. Elwakeel, Environmental application of chitosan resins for the treatment of water and wastewater: a review, Journal of dispersion science and technology. 4, 2-26 (2012).

6. W.S. Wan Ngah, A. Kamari, Y.J. Koay, Equilibrium and kinetics studies of adsorption of copper (II) on chitosan and chitosan/PVA beads, International Journal of Biological Macromolecules, 34, 155-161 (2004).

7. J.R. Mendeza,, R. M. Zepedab, E. L Ramosb, P.E. Floresa, K. Shirai, Chitosan selectivity for removing cadmium (II), copper (II), and lead (II)from aqueous phase: pH and organic matter effect, Journal of hazardous materials. 162, 503511 (2009).

8. M. Ariffin Abu hassan, T. Peili, Z. Z. Noor, Coagulation and flocculation treatment of wastewater in textile industry using chitosan.Journal of Chemical and Natural Resources Engineering, 4(1),43-53 (2009).

9. M. G. Devi, J.J. Dumaran, S. Feroz, Dairy Wastewater Treatment Using Low Molecular Weight Crab Shell Chitosan, J. Inst. Eng. India Ser. E. 93(1), 9-14 (2012).

10. R. Krishna, O. Sahu, Reduction of COD and Color by Polymeric Coagulant (Chitosan). Journal of Polymer and Biopolymer Physics Chemistry, 1,(1), 22-25 (2013).

11. M. T. H. Abou Kana1, M. Radi, M. Z. Elsabee, wastewater treatment with chitosan nanoparticles. International Journal of Nanotechnology, 3(2), 39-50 (2013).

12. M. A. Abd-Elhakeem, T. A. Alkhulaqi. Simple, rapid and efficient water purification by chitosan coated magnetite nanoparticles. J. Environmental Nanotechnology. 3(4), 17-20 (2014).

13. Y. S. Puvvada, S. Vankayalapati, S. Sukhavasi, Extraction of chitin and chitosan from exoskeleton of shrimp for application in the pharmaceutical industry, International Current Pharmaceutical Journal, 1(9), 258-263 (2012).

14. A. Rampinoa, M. Borgognaa, P. Blasi, B. Bellich, A. Cesàro, Chitosan nanoparticles: Preparation, size evolution and stability, International journal of pharmaceutics, 455,(1-2), 219-228 (2013). 
15.D. Merlinaa , P. Salvacion, Investigation of chitosan from squid pen as Scar Remover. World applied sciences journal 5, 98-103 (2009).

16. M. Islam, S. Masum, M. M. Rahman, A. I. Mollab, A. A. Shaikh, S.K. Roy, Preparation of Chitosan from Shrimp Shell and Investigation of Its Properties, International Journal of Basic \& Applied Sciences, 11, 77-80 (2011).

17. M.Kasaai, A review of several reported procedures to determine the degree of $\mathrm{N}$-acetylation for chitin and chitosan using infrared spectroscopy. Carbohydrates Polymer, 71, 497-508(2008). 